This is the author's final, peer-reviewed manuscript as accepted for publication. The publisher-formatted version may be available through the publisher's web site or your institution's library.

\title{
Rotary ultrasonic machining of CFRP/Ti stacks using variable feedrate
}

W. L. Cong, Z. J. Pei, T. W. Deines, D. F. Liu, C. Treadwell

\section{How to cite this manuscript}

If you make reference to this version of the manuscript, use the following information:

Cong, W. L., Pei, Z. J., Deines, T. W., Liu, D. F., \& Treadwell, C. (2013). Rotary ultrasonic machining of CFRP/Ti stacks using variable feedrate. Retrieved from http://krex.ksu.edu

\section{Published Version Information}

Citation: Cong, W. L., Pei, Z. J., Deines, T. W., Liu, D. F., \& Treadwell, C. (2013). Rotary ultrasonic machining of CFRP/Ti stacks using variable feedrate. Composites Part B: Engineering, 52, 303-310.

Copyright: (c) 2013 Elsevier Ltd.

Digital Object Identifier (DOI): doi:10.1016/j.compositesb.2013.04.022

Publisher's Link: http://www.sciencedirect.com/science/article/pii/S1359836813001704

This item was retrieved from the K-State Research Exchange (K-REx), the institutional repository of Kansas State University. K-REx is available at http://krex.ksu.edu 


\title{
Rotary ultrasonic machining of CFRP/Ti stacks using variable feedrate
}

\author{
W.L. Cong, Z.J. Pei ${ }^{*}$, T.W. Deines, \\ Department of Industrial and Manufacturing Systems Engineering, \\ Kansas State University, \\ Manhattan, KS 66506, USA \\ D.F. Liu, \\ College of Mechanical and Electrical Engineering, \\ Central South University, \\ Changsha, Hunan 410083, China \\ C. Treadwell \\ Sonic-Mill, 7500 Bluewater Road NW, \\ Albuquerque, NM 87121, USA
}

\section{Keywords:}

Polymer-matrix composites (PMCs); Joints/joining; Machining; CFRP/Ti stacks

* Corresponding author. Tel.: +1 785532 3436; fax: +1 7855323738.

E-mail address: zpei@ksu.edu (Z.J. Pei). 


\begin{abstract}
Rotary ultrasonic machining (RUM) has been successfully used to drill Ti (titanium and its alloy), CFRP, and CFRP/Ti stacks. In all studies on RUM reported in the literature, feedrate was fixed during each experimental test. It has been shown that low feedrate should be used for RUM of Ti, but RUM of CFRP could be done using feedrate ten times higher. This paper, for the first time, reports a study on RUM of CFRP/Ti stacks using variable feedrate (high feedrate for CFRP and low feedrate for Ti). It also makes comparisons on RUM of CFRP/Ti stacks using fixed and variable feedrate.
\end{abstract}




\section{Introduction}

To decrease fuel consumption, increase aircraft life, and save maintenance cost, carbon fiber reinforced plastic (CFRP) composites are increasingly used in the aircraft industry [Denkena et al., 2008; Davim and Reis, 2003, Lambert, 1987; Sadat, 1995; Guu et al., 2001; Chung, 2010] [Borchure, 2009; Mangalgiri, 1999; Cookson, 2009; Denkena et al., 2008; Garrick, 2007; Kanirura, 2005]. In aircraft assembly, bolting and riveting are currently the preferred methods for fastening CFRP and Ti structural parts [Bennett, 1985, Ramulu et al., 2001; Shyha 2010]. As a result, a large number of holes need to be drilled in CFRP/Ti stacks [Shyha 2010; Boeing web, Zitoune et al., 2010; Ramulu et al., 2001; Massarweh et al, 1992; Shyha 2010; Lambert, 1979].

Problems in drilling of CFRP/Ti stacks using traditional methods include high cutting force and torque [Ramulu et al., 2001; Lambert, 1979] and high tool wear [Lambert, 1979; Ramulu et al., 2001; Weiss 1989], large exit Ti burr [Kim et al., 2001; Ramulu et al., 2001] and composite delamination [Ramulu et al., 2001; Davim and Reis 2003], large groove depth in composite [Weiss 1989], and poor hole quality [Kim et al., 2001; Ramulu et al., 2001]. Rotary ultrasonic machining (RUM) could be a solution to overcome these problems. RUM is illustrated in Figure 1. The cutting tool is a core drill with metal-bonded diamond abrasives. During drilling, the rotating tool vibrates axially at an ultrasonic frequency and moves along its axial direction towards the workpiece. Coolant pumped through the core of the drill washes away the swarf, and prevents the tool from jamming and overheating. 
RUM has been successfully used to drill Ti [Churi et al. 2005, 2006, 2007ab; Cong et al., 2011_Ti], CFRP [Li et al. 2007; Cong et al, 2011, 2012ab], and CFRP/Ti stacks [feasibility study]. In all studies on RUM reported in the literature, feedrate was fixed during each experimental test. It has been shown that, in order to achieve good quality and reasonable tool life, low feedrate (below $0.05 \mathrm{~mm} / \mathrm{s}$ ) should be used in RUM of Ti [Cong et al., 2011a], but feedrate in RUM of CFRP could be ten time higher [Cong et al., 2011bc; 2012ab]. When RUM of CFRP/Ti stacks, if a fixed low feedrate is used, cycle time will be too long; if a fixed high feedrate is used, tool life will be too short. A solution to this dilemma is to use variable feedrate (high feedrate for CFRP and low feedrate for Ti). This paper presents results of such a study. It also makes comparisons on RUM of CFRP/Ti stacks using fixed feedrate and variable feedrate.

There are four sections in this paper. Following this introduction section, Section 2 describes workpiece material properties, experimental set-up, and measurement procedures. Section 3 presents and discusses experimental results. Finally, Section 4 draws conclusions.

\section{Experiments}

\subsection{Properties of workpiece materials}

CFRP/Ti stacks used in this study were formed by joining a CFRP plate $(108 \mathrm{~mm} \times 58 \mathrm{~mm} \times 14$ 
$\mathrm{mm})$ and a Ti plate $(108 \mathrm{~mm} \times 58 \mathrm{~mm} \times 7 \mathrm{~mm})$ together using adhesive (Ultra Bond super glue, Permatex Inc., Solon, OH, USA). The CFRP was composed of carbon fibers and epoxy resin matrix. Plain woven fabric of carbon fibers had an orientation of 0/90 degrees, as illustrated in Figure 2. The carbon fiber yarn in the woven fabric had a thickness of $0.2 \mathrm{~mm}$ and a width of 2.5 mm. The CFRP contained 21 layers of fabric (42 layers of carbon fiber). The Ti workpiece material was titanium alloy (Ti-6Al-4V). Material properties of CFRP and Ti are listed in Table 1 and Table 2, respectively.

\subsection{Experimental set-up}

Experiments were performed on a rotary ultrasonic machine (Series 10, Sonic-Mill, Albuquerque, NM, USA). The experimental set-up is schematically illustrated in Figure 3. It mainly consisted of an ultrasonic spindle system, a data acquisition system, and a coolant system. The ultrasonic spindle system was comprised of an ultrasonic spindle, a power supply, an electric motor, and a control panel. The power supply converted conventional $(60 \mathrm{~Hz})$ electrical supply to high-frequency $(20 \mathrm{kHz})$ electrical energy. This high-frequency electrical energy was provided to a piezoelectric converter that changed high-frequency electrical energy into mechanical vibration. The ultrasonic vibration from the converter was amplified and transmitted to the cutting tool. This caused the cutting tool to vibrate axially at the frequency of $20 \mathrm{kHz}$. The amplitude of ultrasonic vibration could be adjusted by changing the level of output control of the power supply. The motor atop the ultrasonic spindle supplied the rotational motion of the tool and 
different speeds could be obtained by adjusting the motor speed controller on the control panel. The data acquisition system, including dynamometer, charge amplifier, A/D convertor, and computer with software, was used for measurement of cutting force and torque. More details about this system will be described in Section 2.4 (measurement procedures). The coolant system was comprised of pump, coolant tank, pressure regulator, flow rate and pressure gauges, and valves. The coolant system provided coolant to the spindle and the interface of machining.

The cutting tools, as illustrated in Figure 4, were metal-bonded diamond core drills (N.B.R. Diamond Tool Corp., LaGrangeville, NY, USA). The outer and inner diameters (OD and ID) of the cutting tools were $9.54 \mathrm{~mm}$ and $7.82 \mathrm{~mm}$, respectively, and the tuning length was $45 \mathrm{~mm}$. The diamond abrasives had mesh size of $80 / 100$ and concentration of 100 . The metal bond was of B type.

\subsection{Experimental conditions}

Considering the limitations of the experimental set-up (for example, vibration frequency was fixed at $20 \mathrm{kHz}$ on the machine), only the following input variables were changed in the experiments:

- Ultrasonic power: Percentage of power from ultrasonic power supply to control the ultrasonic 
vibration amplitude;

- Tool rotation speed: Rotational speed of cutting tool;

- Feedrate: Feedrate of cutting tool.

Values of these input variables used in this study are listed in Table 3.

Two types of feedrate were used. If using fixed feedrate, the entire hole was drilled using a feedrate of $0.05 \mathrm{~mm} / \mathrm{s}$. If using variable feedrate, feedrate of $0.5 \mathrm{~mm} / \mathrm{s}$ was used to drill CFRP and feedrate of $0.05 \mathrm{~mm} / \mathrm{s}$ was used to drill Ti. Feedrate was changed from $0.5 \mathrm{~mm} / \mathrm{s}$ to 0.05 $\mathrm{mm} / \mathrm{s}$ during a period of $10 \mathrm{~s}$ towards the end of CFRP machining. Figure 5 compared these two different types of feedrate as a function of feeding depth (the distance between workpiece top surface and tool-workpiece interface, as illustrated in Figure 6).

\subsection{Measurement procedures}

A dynamometer (Model 9272, Kistler Inc., Winterthur, Switzerland) was used to measure the cutting force $(\mathrm{Fz})$ in the axial direction and torque. The electrical signals from the dynamometer were amplified by a charge amplifier (Model 5070A, Kistler Inc., Winterthur, Switzerland) and then transformed into digital signals by an A/D converter. After being processed by a signal conditioner, the digital signals were collected by a data acquisition card (PC-CARD-DAS16/16, Measurement Computing Corporation, Norton, MA, USA) on a computer with the help of Dynoware software (Type 2815A, Kistler Inc., Winterthur, Switzerland). The sampling rate was 
$20 \mathrm{~Hz}$. The measured cutting force fluctuated with time within a certain range, as illustrated in Figure 7. The maximum cutting force of the cutting force-time curve was used to represent the cutting force for drilling of each hole. Similarly, the maximum torque of the torque-time curve was used to represent the torque for drilling of each hole. It is noted that the maximum cutting force and torque were obtained during drilling Ti for both types of feedrate.

In this paper, tool wear was defined as the weight loss of the cutting tool during each test. It was the difference between tool weights before and after a test. To remove any residuals left on the tool, the tool was cleaned using methanol and acetone and then was dried using a hand dryer before measurement. The weight of the tool was measured by a high-accuracy scale (Model APX-200, Denver Instrument, Denver, CO, USA).

Surface profilometer (Surftest-402, Mitutoyo Corporation, Kanagawa, Japan) was used to measure surface roughness of the hole surface and groove depth. Surface roughness was measured on the machined surfaces of CFRP and Ti along the axial direction of the hole. The surface roughness reported in this paper was Ra (average surface roughness). The test range and cut-off length of surface roughness measurement were set at $4 \mathrm{~mm}$ and $0.8 \mathrm{~mm}$, respectively. Groove depth (CFRP material near the interface between CFRP and Ti was overcut and a groove was formed) was measured on machined CFRP surface near the interface between CFRP and Ti. The details of measurement were illustrated in Figure 8. For both surface roughness and groove 
depth, four measurements were performed with $90^{\circ}$ between two adjacent measurements. Each measurement was repeated twice. For each hole, there were eight values and the average of these eight values was used.

\section{Results and discussion}

\subsection{Cycle time}

Cycle time was the period of time it took to drill a hole through a CFRP/Ti stack. Figure 9 shows a comparison of cycle time between using fixed and variable feedrate. Compared with cycle time of $426 \mathrm{~s}$ using fixed feedrate, cycle time using variable feedrate was about $200 \mathrm{~s}$.

\subsection{Cutting force}

Figure 10 shows a comparison of cutting force between using fixed and variable feedrate at different levels of ultrasonic power. In Figure 10 (as well as Figures $11-19$ ), each data point is the average value for the four holes drilled under one test condition. Error bars represent the minimum and maximum values among the four holes. It also can be seen from Figure 10 that cutting force using variable feedrate was lower than that using fixed feedrate at every level of ultrasonic power. The differences in cutting force between using fixed and variable feedrate were about the same when ultrasonic power was $0 \%, 20 \%$, or $60 \%$. When ultrasonic power was $40 \%$, the largest difference occurred. 
A comparison of cutting force between using fixed and variable feedrate at different levels of tool rotation speed is shown in Figure 11. Using fixed feedrate always led to higher cutting force than using variable feedrate at all levels of tool rotation speed. The differences in cuttings force between using fixed and variable feedrate were not the same at different levels of tool rotation speed. When tool rotation speed was $2000 \mathrm{rpm}$, the difference in cutting force between using fixed variable feedrate was the largest. When tool rotation speed was $7000 \mathrm{rpm}$, the difference in cutting force was smallest.

\subsection{Torque}

Figure 12 compares toque between using fixed and variable feedrate at different levels of ultrasonic power. Using fixed feedrate led to larger torque than using variable feedrate at all levels of ultrasonic power. Difference in torque between using fixed and variable feedrate reached the maximum when ultrasonic power was $20 \%$ and reached the minimum when ultrasonic power was $0 \%$.

A comparison of torque between using fixed and variable at different levels of tool rotation speed is shown in Figure 13. At all levels of tool rotation speed, torque using variable feedrate was smaller than that using fixed feedrate except when the tool rotation speed was $7000 \mathrm{rpm}$ where torque using variable feedrate was slightly larger than that using fixed feedrate. The difference in torque between using fixed and variable feedrate varied at different levels of tool rotation speed. 
The difference in torque reached the maximum when tool rotation speed was $2000 \mathrm{rpm}$, and reached the minimum when tool rotation speed was $7000 \mathrm{rpm}$.

\subsection{Tool wear}

Figure 14 compares tool wear (tool weight loss) between using fixed and variable feedrate at different levels of ultrasonic power. When ultrasonic power was $0 \%, 20 \%$, or $40 \%$, tool weight loss using fixed feedrate was larger than that using variable feedrate. However, when ultrasonic power was $60 \%$, tool weight loss using fixed feedrate was smaller than that using variable feedrate. The difference in tool wear between using fixed and variable feedrate reached the maximum when ultrasonic power was $0 \%$ and reached the minimum when ultrasonic power was $40 \%$.

A comparison of tool wear (tool weight loss) between using fixed and variable feedrate at different levels of tool rotation speed is shown in Figure 15. When tool rotation speed was 2000 or $3000 \mathrm{rpm}$, tool wear using variable feedrate was larger than that using fixed feedrate. In contrast, when tool rotation speed was 4000 or $7000 \mathrm{rpm}$, the difference in tool wear was negligible; and when tool rotation speed was 5000 or $6000 \mathrm{rpm}$, tool wear using variable feedrate was larger than that using fixed feedrate. The difference in tool wear between using fixed and variable feedrate, tool wear using both fixed and variable feedrate, reached the maximum when tool rotation speed was $2000 \mathrm{rpm}$. 


\subsection{Surface roughness}

Figure 16 (a) compares surface roughness on machined CFRP surface between using fixed and variable feedrate at different levels of ultrasonic power. Using variable feedrate led to higher surface roughness than using fixed feedrate at all levels of ultrasonic power. The difference in surface roughness between using fixed and variable feedrate was the smallest when ultrasonic power was $0 \%$ and largest when ultrasonic power was $60 \%$.

Figure 16 (b) compares surface roughness on machined Ti surface between using fixed and variable feedrate at different levels of ultrasonic power. Using fixed feedrate led to higher surface roughness than using variable feedrate when ultrasonic power was $0 \%$ or $20 \%$, whereas, using fixed feedrate led to lower surface roughness than using variable feedrate when ultrasonic power was $60 \%$. Surface roughness using fixed feedrate was similar to that using variable feedrate when ultrasonic power was $40 \%$. Difference in surface roughness between using fixed and variable feedrate at $0 \%$ of ultrasonic power was larger than that at $20 \%, 40 \%$, or $60 \%$ of ultrasonic power.

Figure 17 (a) compares of surface roughness on machined CFRP surface between using fixed and variable feedrate at different levels of tool rotation speed. Surface roughness using fixed feedrate was lower than that using variable feedrate at all levels of tool rotation speed. The 
difference in surface roughness between using fixed and variable feedrate was less than $1 \mu \mathrm{m}$. The maximum and minimum of difference were observed when tool rotation speed was 7000 and $4000 \mathrm{rpm}$, respectively.

Figure 17 (b) compares surface roughness on machined Ti surface between using fixed and variable feedrate at different levels of tool rotation speed. When tool rotation speed was 2000 rpm, using variable feedrate led to remarkably higher surface roughness than using fixed feedrate. When tool rotation speed was 3000 or $4000 \mathrm{rpm}$, surface roughness was similar using both types of feedrate. However, when tool rotation speed was from 5000 to $7000 \mathrm{rpm}$, using variable feedrate led to smaller surface roughness than using fixed feedrate.

\subsection{Groove depth}

A comparison of groove depth between using fixed and variable feedrate at different levels of ultrasonic power is shown in Figure 18. At each level of ultrasonic power, groove depth using variable feedrate was larger than that using fixed feedrate. The difference in groove depth between using fixed and variable feedrate decreased with the increase of ultrasonic power.

Figure 19 compares groove depth between using fixed and variable feedrate at different levels of tool rotation speed. At all levels of tool rotation speed, groove depth using variable feedrate was larger than that using fixed feedrate. The largest difference in groove depth between using fixed 
and variable feedrate was at $2000 \mathrm{rpm}$, and the smallest difference was obtained when tool rotation speed was $6000 \mathrm{rpm}$ where the values of groove depth overlapped using both types of feedrate.

\section{Conclusions}

This paper reports a study on rotary ultrasonic machining (drilling) of CFRP/Ti stacks - using variable feedrate (using a faster feedrate to drill CFRP and a slower feedrate to drill Ti). Comparisons between using fixed and variable feedrate at different levels of ultrasonic power and tool rotation speed have been made.

The following conclusions are drawn from this study:

(a) Cycle time using variable feedrate was shorter than that using fixed feedrate.

(b) Using variable feedrate led to a lower cutting force than using fixed feedrate at all levels of ultrasonic power and tool rotation speed. This was true for torque at all levels of ultrasonic power and all levels of tool rotation speed except for $7000 \mathrm{rpm}$.

(c) When ultrasonic power was low $(0 \%, 20 \%$, and $40 \%)$, using variable feedrate led to lower tool wear than using fixed feedrate. When tool rotation speed was $2000 \mathrm{rpm}$, using variable feedrate led to remarkably higher tool wear than using fixed feedrate

(d) Using variable feedrate always led to higher surface roughness on machined CFRP surface. When ultrasonic vibration was off, using variable feedrate resulted in 
remarkably lower surface roughness on machined Ti surface than using fixed feedrate. When tool rotation speed was $2000 \mathrm{rpm}$, using variable feedrate led to higher surface roughness on machined Ti surface than using fixed feedrate.

(e) Using variable feedrate led to larger groove depth at all levels of ultrasonic power than using fixed feedrate.

\section{Acknowledgements}

The work was supported by the National Science Foundation through award CMMI-0900462. The authors gratefully extend their acknowledgements to N.B.R. Diamond Tool Corp. for supplying the cutting tools.

\section{References}

[Boeing website] 787 Dreamliner Program Fact Sheet, available at: http://www.boeing.com/commercial/787family/programfacts.html, Accessed on June 24, 2012.

[Brinksmeier and Janssen, 2002] Brinksmeier E., and Janssen R., 2002, Drilling of multi-layer composite materials consisting of carbon fiber reinforced plastics (CFRP), titanium and aluminum alloys, CIRP Annals - Manufacturing Technology, 51(1), pp. 87-90.

[Brochure, 2009] Brochure, 2009, The Global Aerospace Market Trends and Forecast 2009-2028, available at: 
http://www.researchandmarkets.com/reports/1086286/the global aerospace market trends and forecast, Accessed on June 24, 2012.

[Chung, 2010] Chung D.D.L., 2010, Composite Materials Science and Applications, Second edition, Springer-Verlag London Ltd., London, UK.

[Churi et al., 2005] Churi N.J., Li Z.C., Pei Z.J., and Treadwell C., 2005, Rotary ultrasonic machining of titanium alloy: a feasibility study, Proceedings of the 2005 ASME International Mechanical Engineering Congress and Exposition (IMECE 2005), Orlando, FL, USA, November 5-11, pp. 885-892.

[Churi et al., 2006] Churi N.J., Pei Z.J., and Treadwell C., 2006, Rotary ultrasonic machining of titanium alloy: effects of machining variables, Machining Science and Technology 10(3), pp. 301-321.

[Churi et al., 2007a] Churi N.J., Pei Z.J., and Treadwell C., 2007a, Rotary ultrasonic machining of titanium alloy (Ti-6Al-4V): effects of tool variables, International Journal of Precision Technology, 1(1), pp. 85-96.

[Churi et al., 2007b] Churi N.J., Pei Z.J., and Treadwell C., 2007b, Wheel wear mechanisms in rotary ultrasonic machining of titanium, Proceedings of the 2007 ASME International Mechanical Engineering Congress and Exposition (IMECE 2007), Seattle, WA, USA, November 11-15, pp. 399-407.

[Colligan, 1994] Colligan K., 1994, New tool drills both titanium and carbon composites, American Machinist, (10), pp.56-58. 
[Cong et al., 2011a] Cong W.L., Pei Z.J., Feng Q., Deines T.W., and Treadwell C., 2011, Experimental study on cutting temperature in rotary ultrasonic machining, Proceedings of NAMRI/SME, 39, pp. 369-376.

[Cong et al., 2011b] Cong W.L., Pei Z.J., Deines T.W., and Treadwell C., 2011, Rotary ultrasonic machining of CFRP using cold air as coolant: feasible regions, Journal of Reinforced Plastics and Composites, 30(10), pp. 899-906.

[Cong et al., 2011c] Cong W.L., Feng Q., Pei Z.J., Deines T.W., and Treadwell C., 2011, Dry machining of carbon fiber reinforced plastic composite by rotary ultrasonic machining: effects of machining variables, Proceedings of the ASME 2011 International Manufacturing Science and Engineering Conference (MSEC), Corvallis, OR, USA, June 13-17, MSEC2011-50116.

[Cong et al., 2012a] Cong W.L., Pei Z.J., Feng Q., Deines T.W., and Treadwell C., 2012, Rotary ultrasonic machining of CFRP: a comparison with twist drilling, Journal of Reinforced Plastics and Composite, 31(5), pp. 313-321.

[Cong et al., 2012b] Cong W.L., Pei Z.J., Feng Q., Deines T.W., and Treadwell C., 2012, Rotary ultrasonic machining of carbon fiber reinforced plastic composites: using cutting fluid versus cold air as coolant, Journal of Composite Materials, 46(14), pp. 1747-1753.

[Cookson, 2009] Cookson I., 2009, Sector outperforms: 2008 M\&A activity matches prior-year record, Aerospace Components, (February), pp.1-5

[Davim and Reis, 2003] Davim J.P., and Reis P., 2003, Drilling carbon fiber reinforced plastics manufactured by autoclave-experimental and statistical study, Materials and Design, 
24(5), pp. 315-324.

[Denkena et al., 2008] Denkena B., Boehnke D., Dege J.H., 2008, Helical milling of CFRP-titanium layer compounds, CIRP Journal of manufacturing Science and Technology, 1(2), pp. 64-69.

[Garrick, 2007] Garrick R., 2007, Drilling advanced aircraft structures with PCD (Poly-Crystalline Diamond) Drills, AeroTech Congress \& Exhibition, Los Angeles, CA, USA, September 18-20.

[Guu et al., 2001] Guu Y.H., Hocheng H., Tai N.H., and Liu S.Y., 2001, Effect of electrical discharge machining on the characteristics of carbon fiber reinforced carbon composites, Journal of Materials Science, 36(8), pp. 2037-2043.

[Kim and Lee, 2005] Kim G.W., and Lee K.Y., 2005, Critical thrust force at propagation of delamination zone due to drilling of FRP/metallic strips, Composite Structures, 69(2), pp. $137-141$.

[Kim and Ramulu, 2004] Kim D., and Ramulu M., 2004, Drilling process optimization for graphite/bismaleimide-titanium alloy stacks, Composite Structures, 63(1), pp. 101-114.

[Kim and Ramulu, 2005] Kim D., and Ramulu M., 2005, Cutting and drilling characteristics of hybrid titanium composite laminate (HTCL), 37th Proceedings of materials and processing technologies for revolutionary applications fall technical conference, Seattle, WA, USA, October 31 - November 3, pp. 1-8.

[Kim and Ramulu, 2005] Kim D., and Ramulu M., 2005, Study on the drilling of 
Titanium/Graphite hybrid composites, ASME International Mechanical Engineering Congress and Exposition, Orlando, FL, USA, November 5-11, pp. 99-106.

[Kim and Ramulu, 2005] Kim D., and Ramulu M., 2005, Study on the drilling of titanium/Graphite hybrid composites, Journal of Engineering Materials and Technology, 129(3), pp. 390-396.

[Kim et al. 2001] Kim D., Ramulu M., Garbini J., 2001, Hole quality in drilling of Graphite/Bismalemide-Titanium stacks, 33rd International SAMPE Technical Conference, Seattle, WA, USA, November 5-8, pp. 1315-1326.

[Kim et al., 2005] Kim D., Ramulu M., and Pedersen W., 2005, Machinability of titanium/graphite hybrid composites in drilling, Transactions of NAMRI/SME, 33, pp. 445-452.

[Lambert, 1987] Lambert B.K., 1987, Cutting and drilling of composite materials, The Carbide and Tool Journal, 19(5), pp. 31-34.

[Li et al., 2007] Li Z.C., Pei Z.J., Sisco T., Micale A.C., and Treadwell C., 2007, Experimental study on rotary ultrasonic machining of graphite/epoxy panel, ASPE Spring Topical Meeting on Vibration Assisted Machining Technology, Chapel Hill, NC, USA, April 16-17, pp. 52-57.

[Mallick, 1997] Mallick P.K., 1997, Composite Engineering Handbook, Marcel Dekker Inc., New York, NY, USA.

[Mangalgiri, 1999] Mangalgiri P.D., 1999, Composite materials for aerospace application, Bulletin of Material Science, 22(3), pp. 657-664. 
[Margolis 2006] Margolis D., Stacking the odds, Cutting Tool Engineering, (8), pp. 74-80.

[Ramulu et al., 2001] Ramulu M., Branson T., Kim D., 2001, A study on the drilling of composite and titanium stacks, Composite Structures, 54(10), pp. 67-77.

[Sadat, 1995] Sadat A.B., 1995, Delamination and other types of damage of graphite/epoxy composite caused by machining, American Society of Mechanical Engineers, Applied Mechanics Division, 208, pp. 41-52.

[Schwartz, 1992] Schwartz M.M., 1992, Composite Materials Handbook, Second edition, McGraw-Hill, Columbus, OH, USA.

[Shyha et al., 2010] Shyha I.S., Soo S.L., Aspinwall D.K., Bradley S., Dawson S., and Pretorius C.J., 2010, Drilling of titanium/CFRP/Aluminum stacks, Key Engineering Materials, 447-448, pp. 624-633.

[Weiss, 1989] Weiss R.A., 1989, Portable air feed peck drilling of graphite composite, titanium and other materials in dissimilar combinations, FASTEC '89, Arlinton, Texas, USA, Octomber 4-6.

[Yagishita, 2008] Yagishita H., Comparing drilling and circular milling for hole making in bi-layer composite materials consisting of carbon fiber reinforced plastic (CFRP) laminates and titanium alloys, Transactions of NAMRI/SME, 36, pp. 17-24.

[Zitoune et al., 2010] Zitoune R., Krishnaraj V., Collombet F., 2010, Study of drilling of composite material and aluminium stack, Composite Structures, 92(5), pp. 1246-1255. 
Table 1. Material properties of CFRP and its components.

\begin{tabular}{lcc}
\hline Property & Unit & Value \\
\hline Density of CFRP & $\mathrm{kg} / \mathrm{m}^{3}$ & 1550 \\
Hardness (Rockwell) & $\mathrm{HRB}$ & $70-75$ \\
Density of epoxy matrix & $\mathrm{kg} / \mathrm{m}^{3}$ & 1200 \\
Elastic modulus of epoxy matrix & $\mathrm{GPa}$ & 4.5 \\
Tensile strength of epoxy matrix & $\mathrm{MPa}$ & 130 \\
Poisson's ratio of epoxy matrix & & 0.2 \\
Density of carbon fiber & $\mathrm{kg} / \mathrm{m}^{3}$ & 1800 \\
Elastic modulus of carbon fiber & $\mathrm{GPa}$ & 230 \\
Tensile strength of carbon fiber & $\mathrm{GPa}$ & 5 \\
Poisson's ratio of carbon fiber & & 0.3 \\
Melting point of carbon fiber & ${ }^{\circ} \mathrm{C}$ & 3552 \\
\hline
\end{tabular}

Table 2. Material properties of titanium alloy (Ti-6Al-4V).

\begin{tabular}{lcc}
\hline Property & Unit & Value \\
\hline Density & $\mathrm{kg} / \mathrm{m}^{3}$ & 4510 \\
Hardness (Rockwell) & $\mathrm{HRC}$ & 36 \\
Elastic modulus & $\mathrm{GPa}$ & 113.8 \\
Tensile strength & $\mathrm{MPa}$ & 950 \\
Melting point & ${ }^{\circ} \mathrm{C}$ & 1660 \\
\hline
\end{tabular}

Table 3. Input variables and their values.

\begin{tabular}{lcl}
\hline Variable & Unit & \multicolumn{1}{c}{ Value } \\
\hline Ultrasonic power & $\%$ & $0 ; 20 ; 40 ; 60$ \\
Tool rotation speed & $\mathrm{rpm}$ & $2000 ; 3000 ; 4000 ; 5000 ; 6000 ; 7000$ \\
Feedrate & $\mathrm{mm} / \mathrm{s}$ & 0.05 (Fixed); 0.5 / 0.05 (Variable) \\
\hline
\end{tabular}




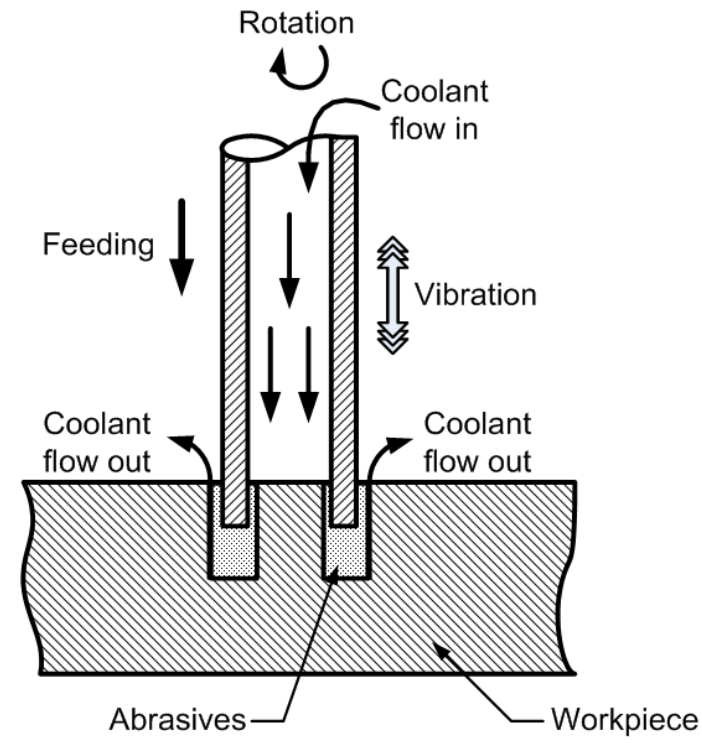

Figure 1 Illustration of rotary ultrasonic machining.

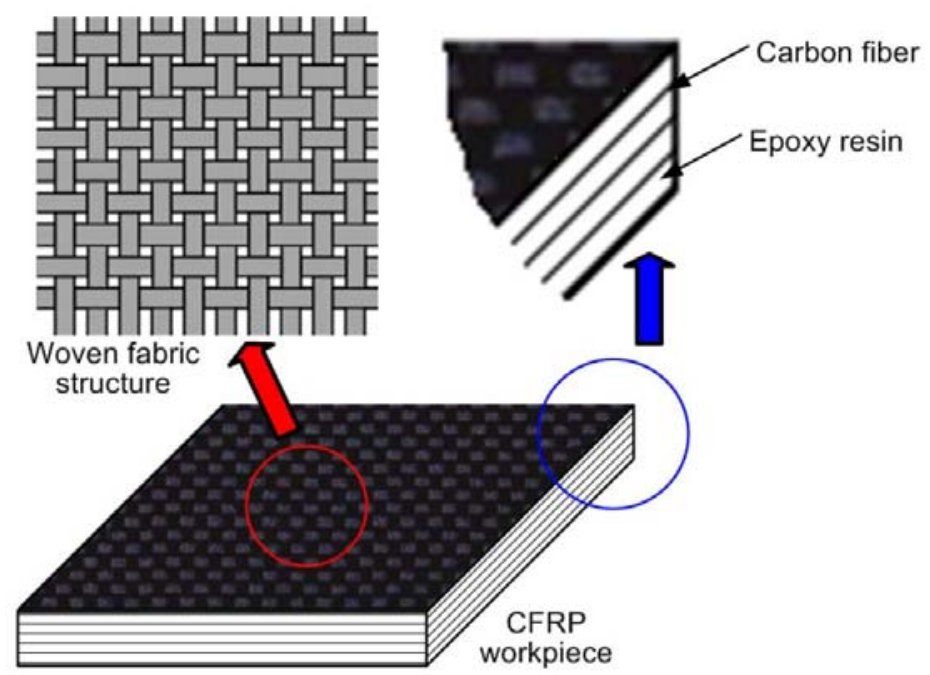

Figure 2 Illustrations of woven fabric and CFRP structures. 


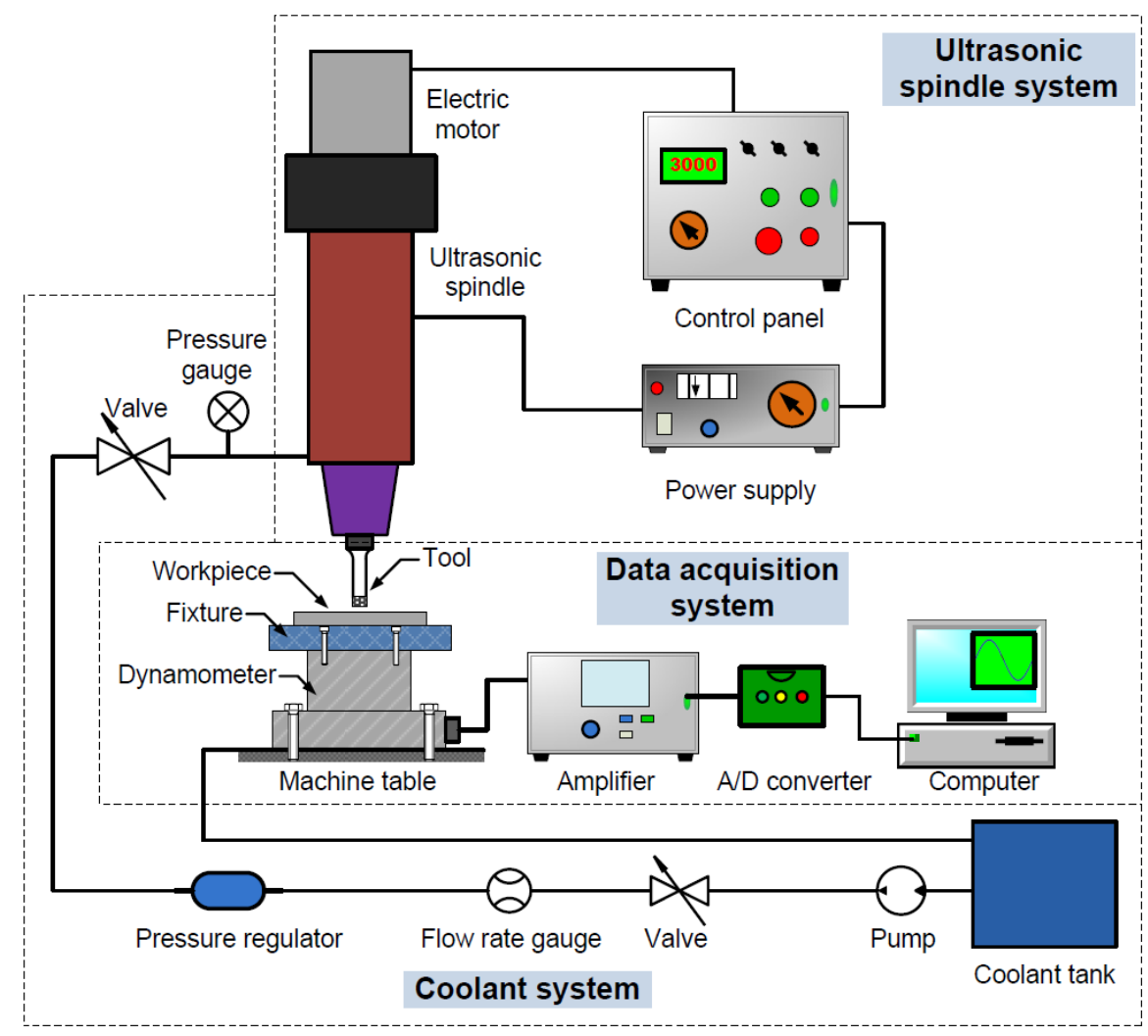

Figure 3 RUM experimental set-up.

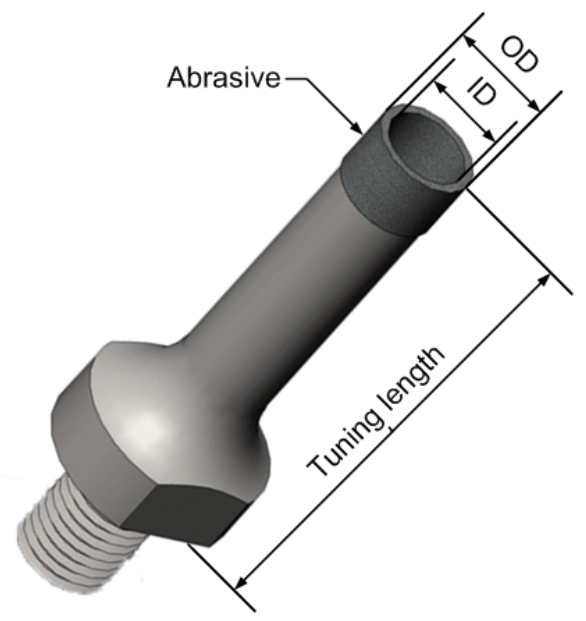

Figure 4 Illustration of RUM cutting tool. 


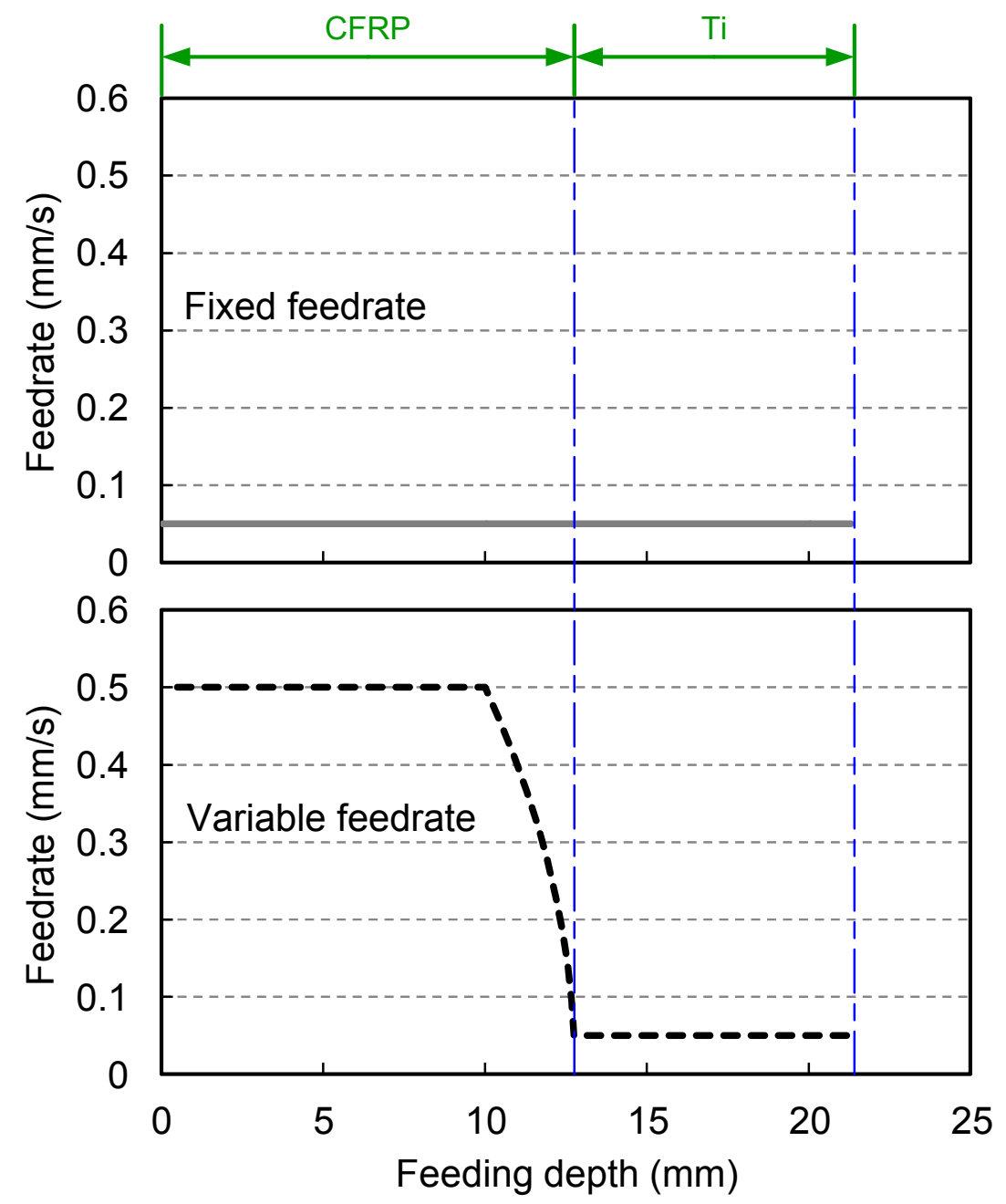

Figure 5 Illustrations of fixed feedrate and variable feedrate. 


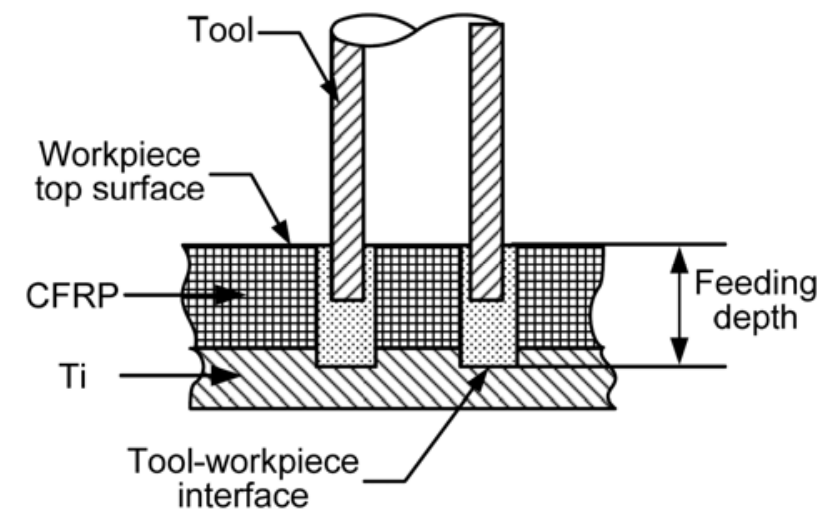

Figure 6 Illustration of feeding depth. 

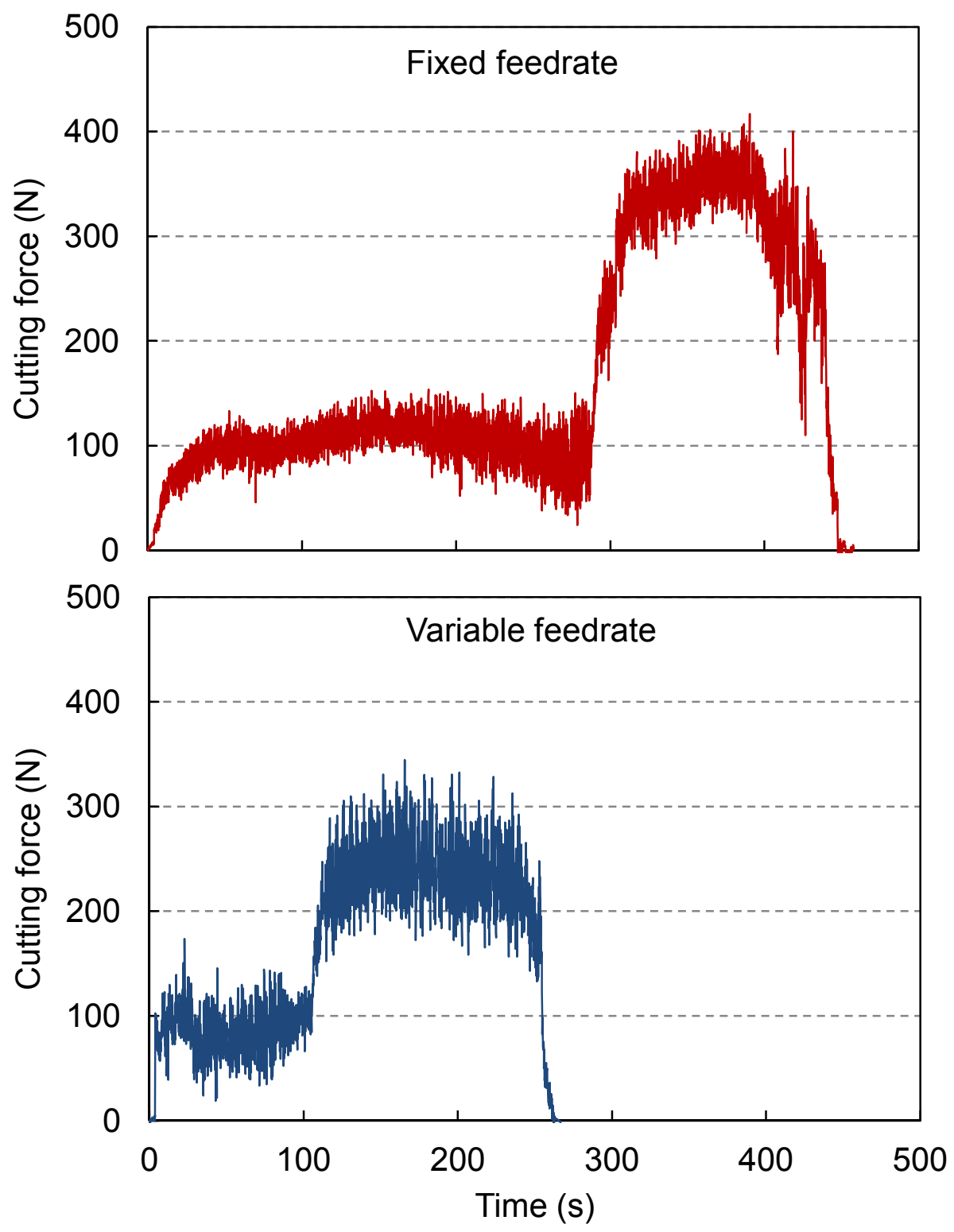

Figure 7 Typical cutting force-time curves using fixed and variable feedrate. 

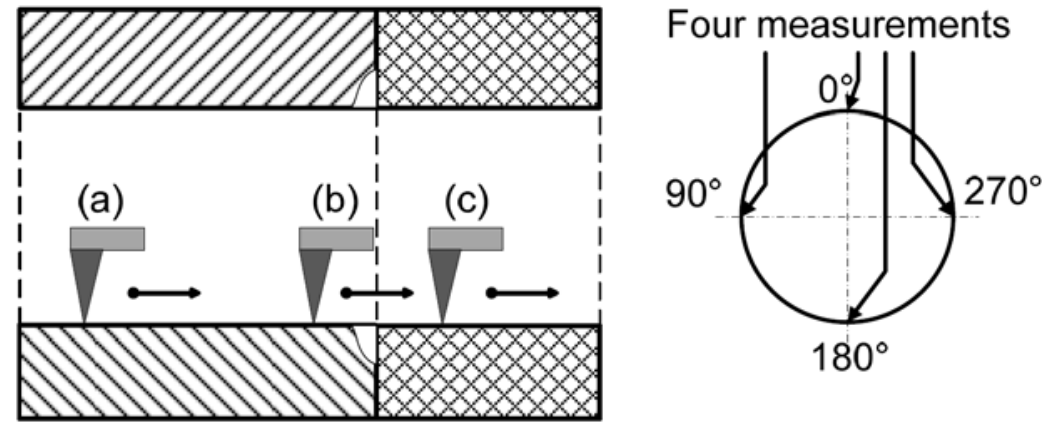

CFRP

$\mathrm{Ti}$
(a) CFRP surface roughness measurement
(b) CFRP groove depth measurement
(c) Ti surface roughness measurement

Figure 8 Surface roughness and groove depth measurements.

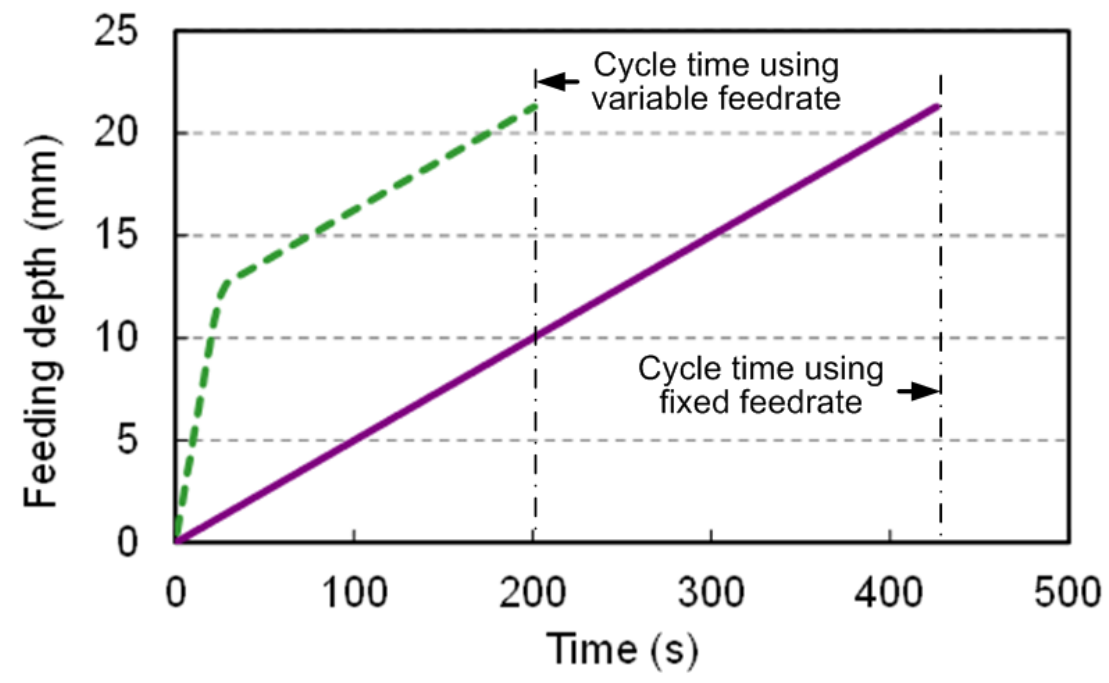

Figure 9 Comparison of cycle time. 


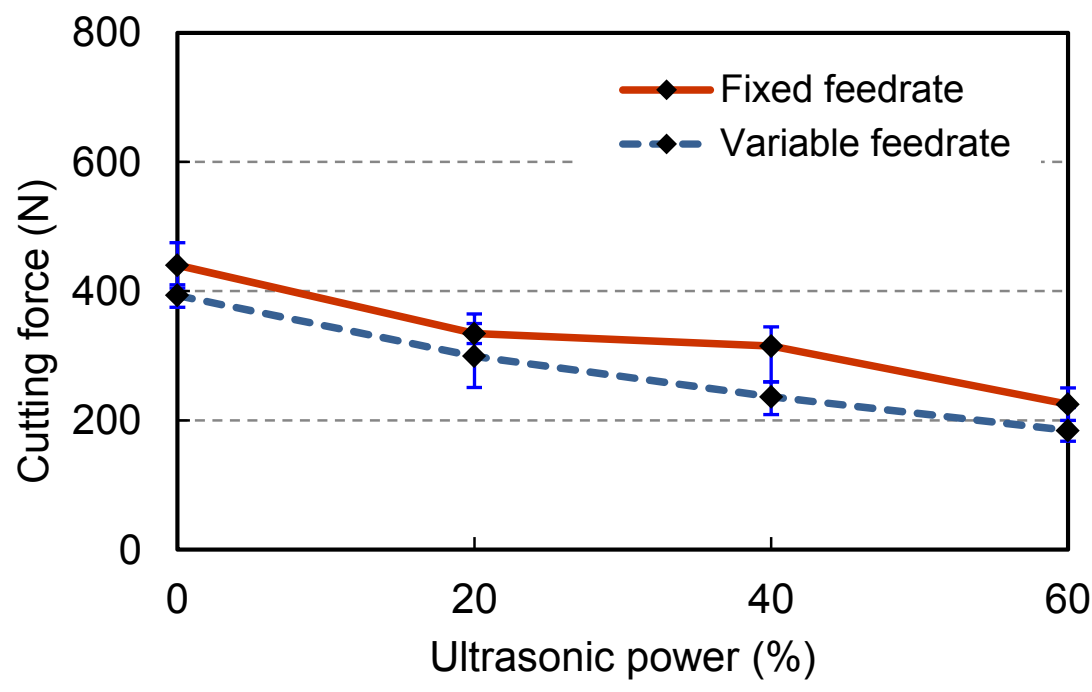

Tool rotation speed $=4000 \mathrm{rpm}$

Feedrate $=0.05 \mathrm{~mm} / \mathrm{s}$ (using fixed feedrate)

Feedrate $=0.5 / 0.05 \mathrm{~mm} / \mathrm{s}$ (using variable feedrate)

Figure 10 Comparison of cutting force at different levels of ultrasonic power.

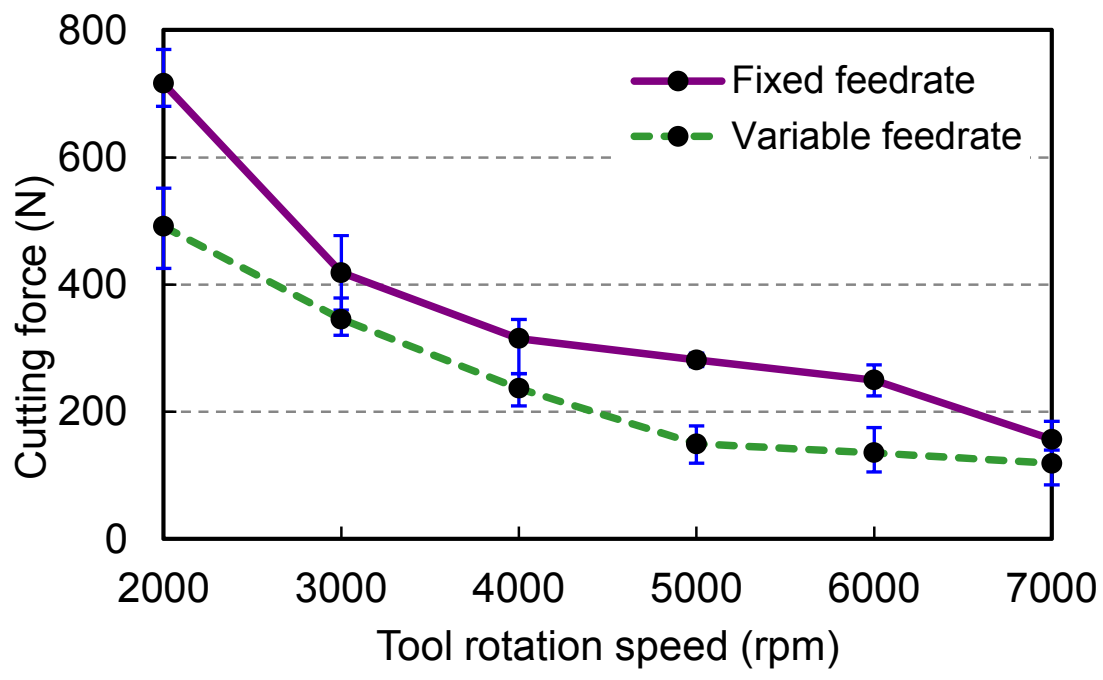

Ultrasonic power $=40 \%$

Feedrate $=0.05 \mathrm{~mm} / \mathrm{s}$ (using fixed feedrate)

Feedrate $=0.5 / 0.05 \mathrm{~mm} / \mathrm{s}$ (using variable feedrate)

Figure 11 Comparison of cutting force at different levels of tool rotation speed 


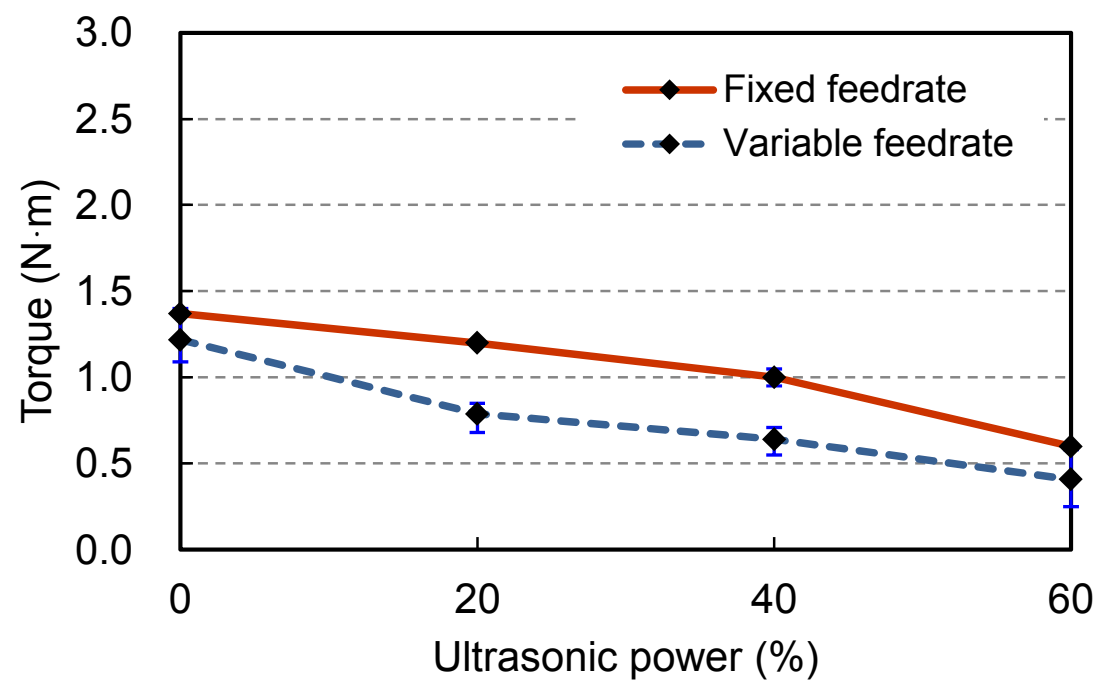

Tool rotation speed $=4000 \mathrm{rpm}$

Feedrate $=0.05 \mathrm{~mm} / \mathrm{s}$ (using fixed feedrate)

Feedrate $=0.5 / 0.05 \mathrm{~mm} / \mathrm{s}$ (using variable feedrate)

Figure 12 Comparison of torque at different levels of ultrasonic power.

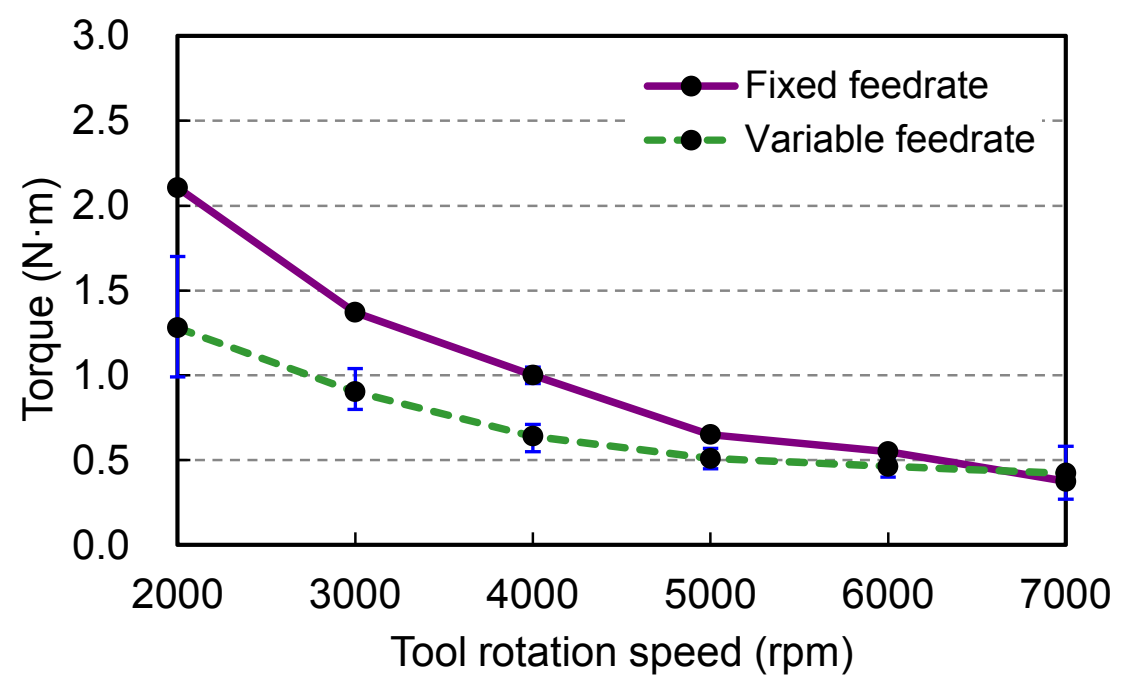

Ultrasonic power $=40 \%$

Feedrate $=0.05 \mathrm{~mm} / \mathrm{s}$ (using fixed feedrate)

Feedrate $=0.5 / 0.05 \mathrm{~mm} / \mathrm{s}$ (using variable feedrate)

Figure 13 Comparison of torque at different levels of tool rotation speed. 


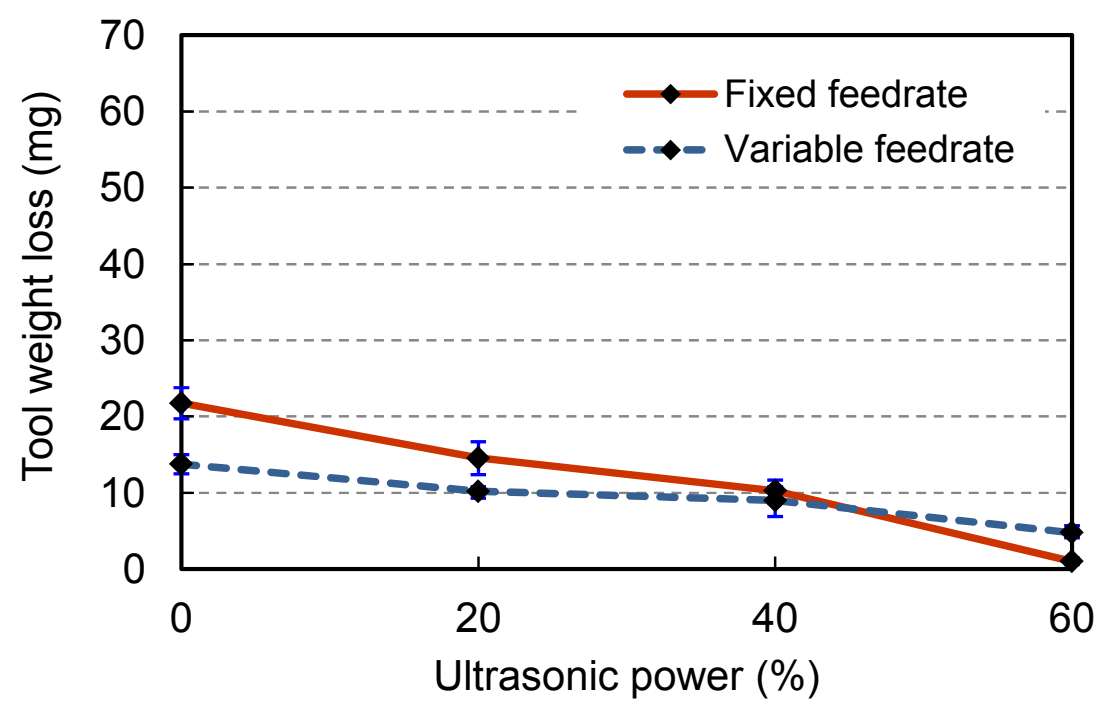

Tool rotation speed $=4000 \mathrm{rpm}$

Feedrate $=0.05 \mathrm{~mm} / \mathrm{s}$ (using fixed feedrate)

Feedrate $=0.5 / 0.05 \mathrm{~mm} / \mathrm{s}$ (using variable feedrate)

Figure 14 Comparison of tool wear at different levels of ultrasonic power.

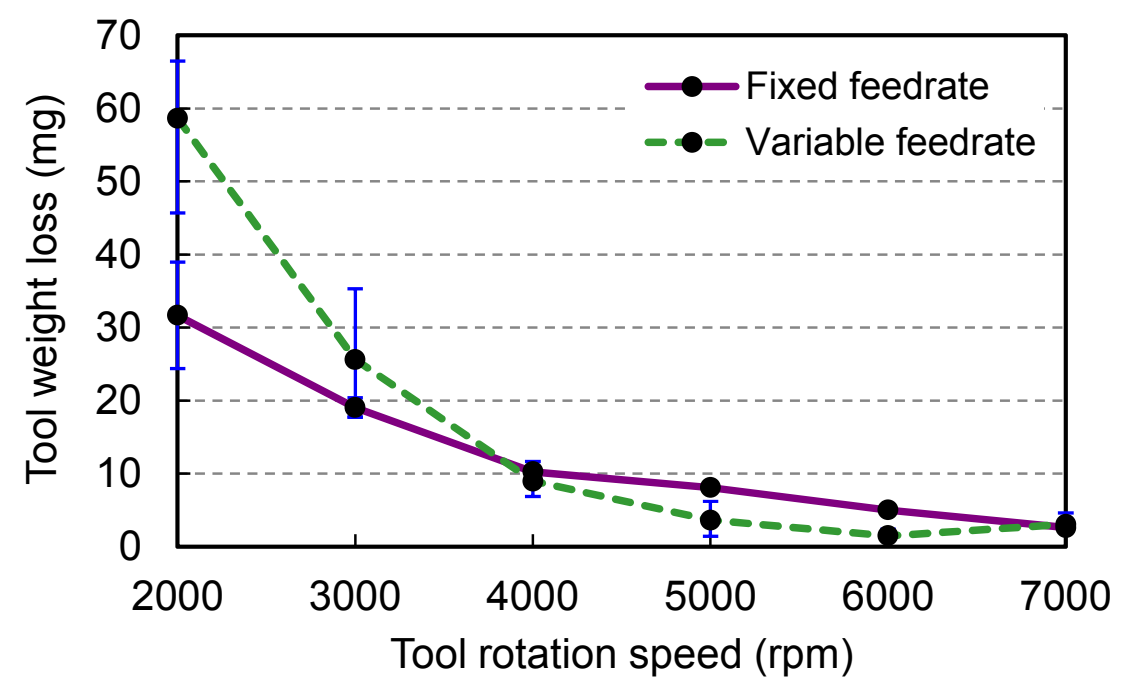

Ultrasonic power $=40 \%$

Feedrate $=0.05 \mathrm{~mm} / \mathrm{s}$ (using fixed feedrate)

Feedrate $=0.5 / 0.05 \mathrm{~mm} / \mathrm{s}$ (using variable feedrate)

Figure 15 Comparison of tool wear at different levels of tool rotation speed. 


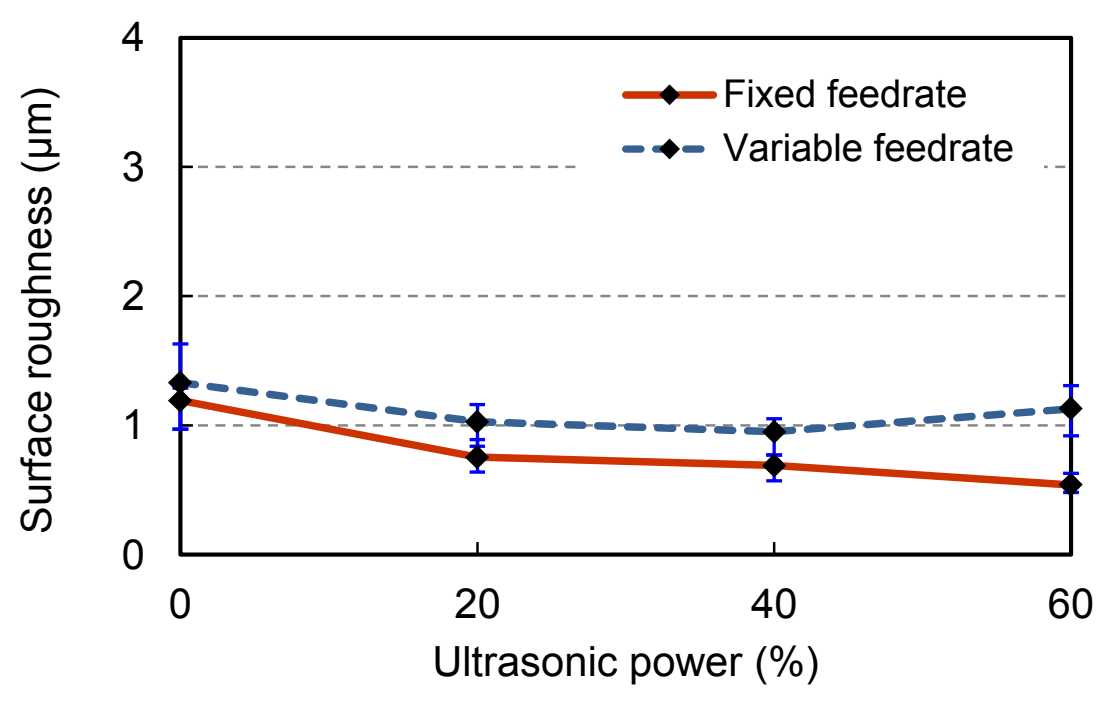

(a) Machined CFRP surface

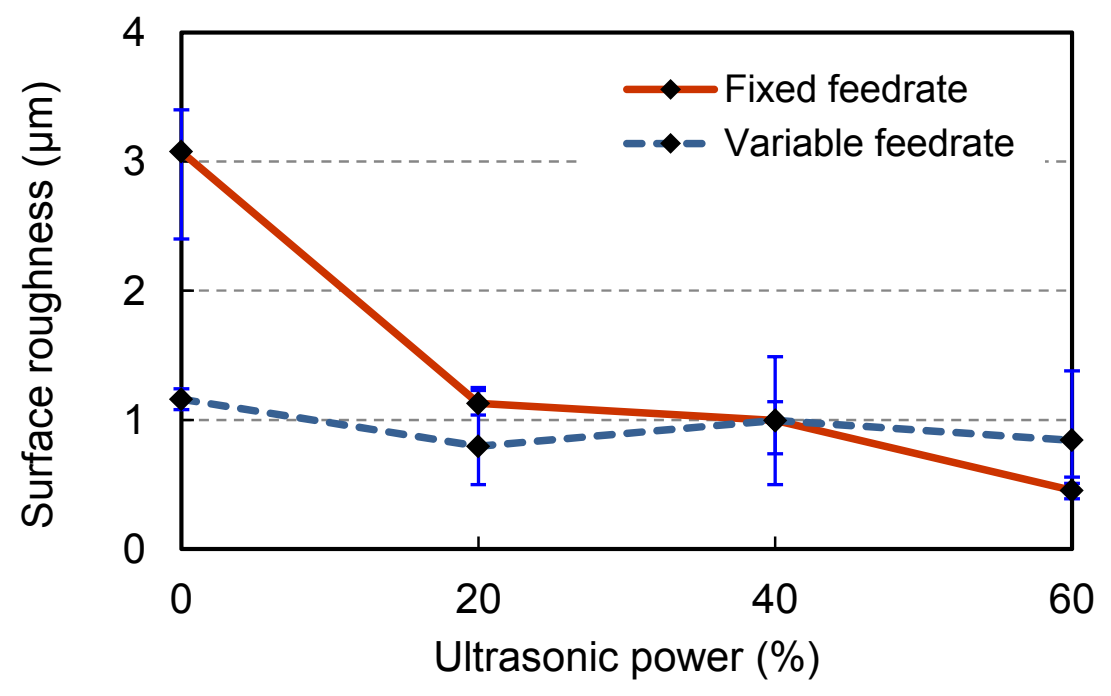

(b) Machined Ti surface

Tool rotation speed $=4000 \mathrm{rpm}$

Feedrate $=0.05 \mathrm{~mm} / \mathrm{s}$ (using fixed feedrate)

Feedrate $=0.5 / 0.05 \mathrm{~mm} / \mathrm{s}$ (using variable feedrate)

Figure 16 Comparison of surface roughness at different levels of ultrasonic power. 


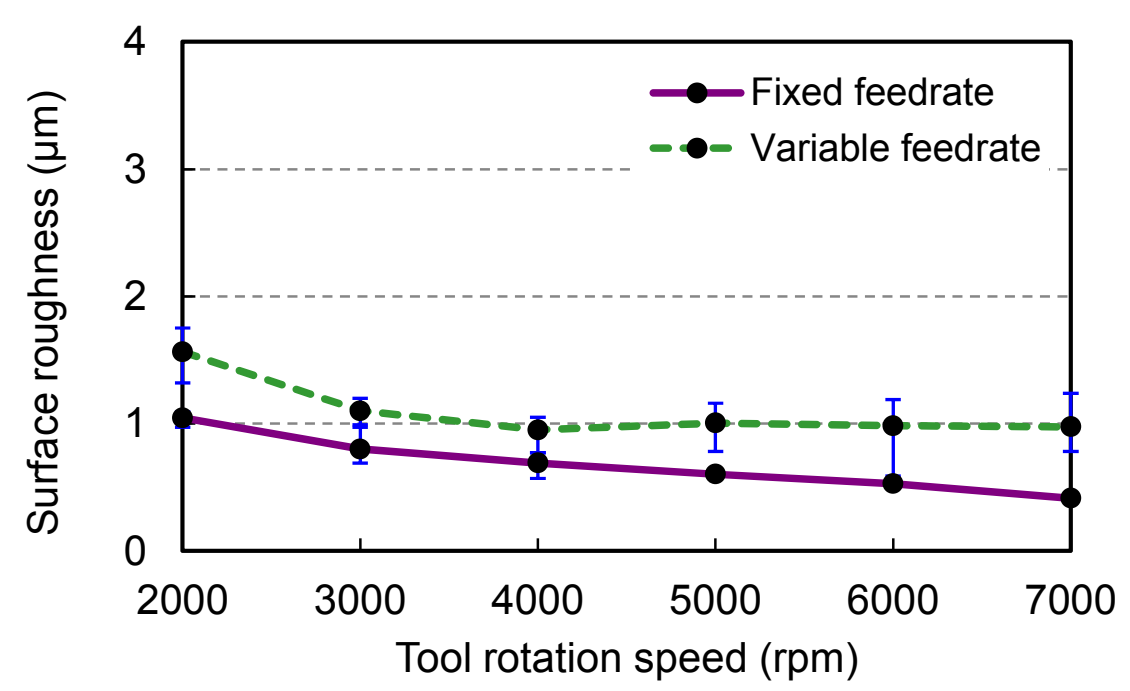

(a) Machined CFRP surface

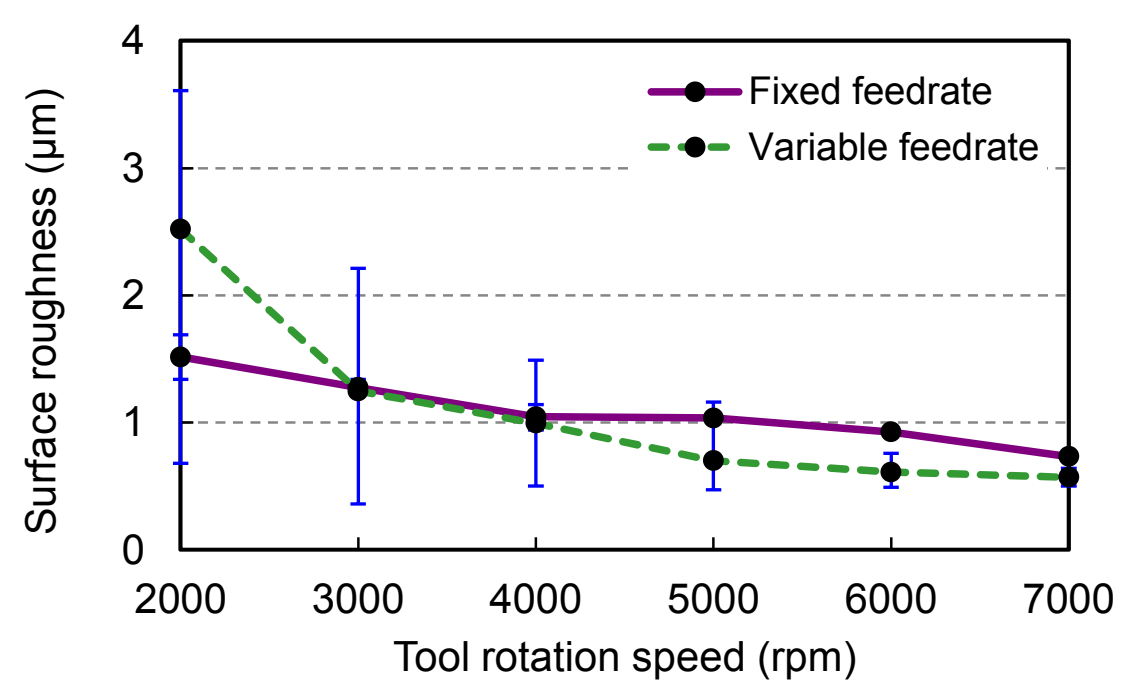

Ultrasonic power $=40 \%$

Feedrate $=0.05 \mathrm{~mm} / \mathrm{s}$ (using fixed feedrate)

Feedrate $=0.5 / 0.05 \mathrm{~mm} / \mathrm{s}$ (using variable feedrate)

Figure 17 Comparison of surface roughness at different levels of tool rotation speed. 


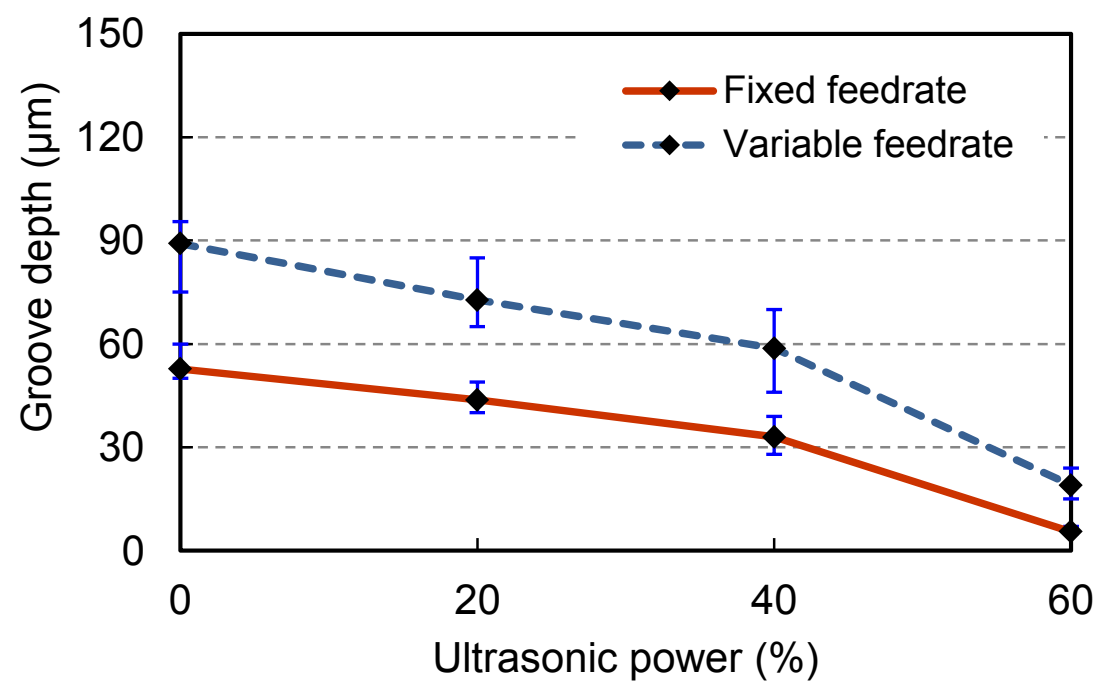

Tool rotation speed $=4000 \mathrm{rpm}$

Feedrate $=0.05 \mathrm{~mm} / \mathrm{s}$ (using fixed feedrate)

Feedrate $=0.5 / 0.05 \mathrm{~mm} / \mathrm{s}$ (using variable feedrate)

Figure 18 Comparison of groove depth at different levels of ultrasonic power.

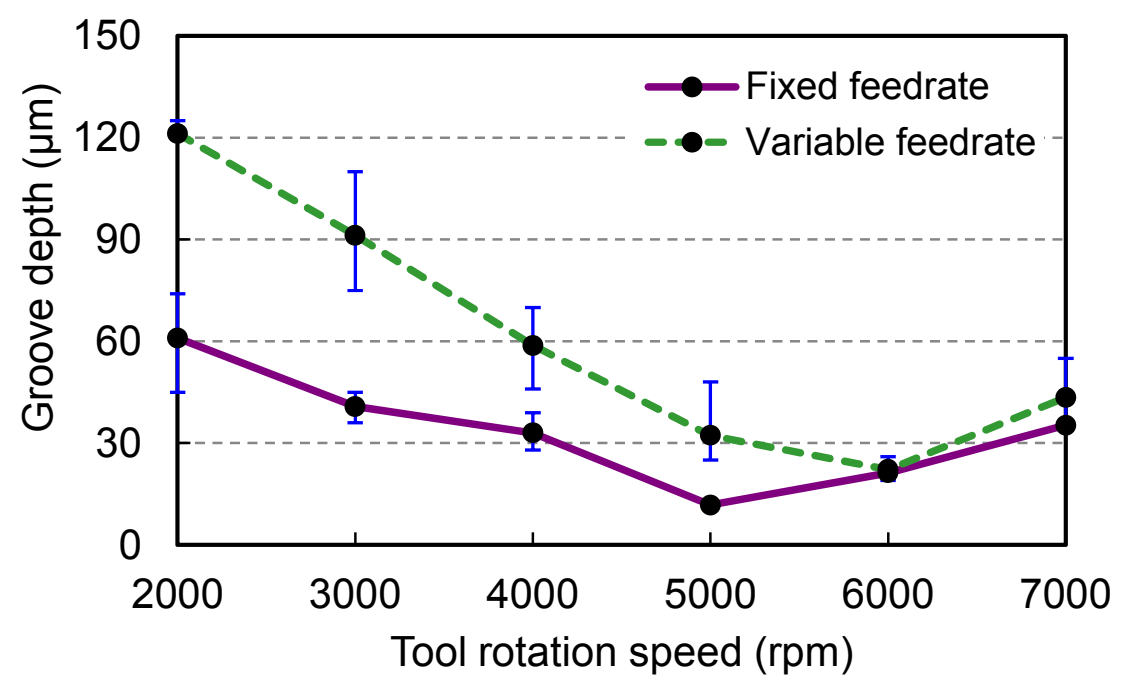

Ultrasonic power $=40 \%$

Feedrate $=0.05 \mathrm{~mm} / \mathrm{s}$ (using fixed feedrate)

Feedrate $=0.5 / 0.05 \mathrm{~mm} / \mathrm{s}$ (using variable feedrate)

Figure 19 Comparison of groove depth at different levels of tool rotation speed. 